\title{
Ese oscuro objeto del deseo: cuerpo y violencia
}

\author{
Alicia H. PULEO \\ Universidad de Valladolid \\ aliciahelda.puleo@uva.es
}

Recibido: Mayo 2015

Aceptado: Junio 2015

\begin{abstract}
RESUMEN
Uno de los procedimientos de legitimación de las prácticas opresivas consiste en reducir a los individuos subordinados a la categoría de mero cuerpo. Tanto la conceptualización de las mujeres como la de los animales no humanos ha tenido lugar en el marco de los dualismos Cultura/Naturaleza, Mente/Cuerpo y Sujeto/Objeto. Su adscripción al elemento devaluado de los opuestos ha expresado y legitimado su condición de blanco privilegiado del deseo y de la violencia simultáneamente. El objeto de deseo, convertido en carne, despierta amor y odio, anhelo de posesión y de aniquilación. Para intentar una mejor comprensión de este fenómeno, este estudio analiza el entramado conceptual que subyace al deseo en la cultura patriarcal.
\end{abstract}

Palabras clave: Ética, mujeres, cuerpo, animal.

\section{That obscure object of desire: body and violence}

\begin{abstract}
One of the ways of legitimizing oppressive practices consists of reducing subordinates to the category of mere body. The conceptualization of women, just as that of non-human animals has taken place within the framework of the Culture / Nature, Mind / Body and Subject / Object dualisms. The ascription to the devalued element of the dualisms has expressed and legitimized the condition of privileged target of desire and of violence simultaneously. This object of desire, turned into meat, arouses love and hate, desire of possession and of annihilation. Endeavouring to comprehend this phenomenon, this study analyzes the conceptual framework that underpins desire in patriarchal culture.
\end{abstract}

Key words: Ethics, women, body, animal.

\section{INTRODUCCIÓN}

En un contexto intelectual con fuerte influencia de la ontología existencialista francesa, influencia recibida en particular a través de El Segundo Sexo de Simone de Beauvoir, resulta significativo que el resurgir del feminismo en los años sesenta del siglo XX tuviera lugar en torno al concepto de persona. No se equivocaron las 
activistas estadounidenses cuando eligieron el concurso de Miss América como blanco de sus críticas. El motivo que las impulsaba no era el rechazo de la belleza, como podría interpretar alguien que desconozca el pensamiento feminista (y, lamentablemente, debemos decir que todavía en el siglo XXI oímos opiniones de este tipo). La razón que sustentaba sus campañas era la voluntad de luchar contra la reificación, forma básica de la injusticia que afectaba a las mujeres y a la que se solía aludir con el término de cosificación. En este trabajo voy a sostener que la cosificación que afecta a mujeres y animales es un elemento determinante en el desencadenamiento de la violencia de la que son víctimas.

\section{MENTES Y CUERPOS}

Beauvoir compartía con Sartre la clasificación de los entes en dos grandes grupos: por un lado, las cosas, que poseen un ser-en-sí, definido, inerte; por otro, los seres humanos que, en tanto conciencias, se caracterizarían por el ser-para-sí, es decir, por carecer de una esencia fija, por ser estructuras proyectantes que se van construyendo a través de sus sucesivas elecciones vitales. En la línea de Heidegger, Sartre afirmaba que "La conscience est un être pour lequel il est dans son être question de son être en tant que cet être implique un être autre que lui » (Sartre, 1943 :29). La dualidad de la conciencia es un resquicio de "nada » que le permite evadirse de la simple identidad del ser de las cosas. Mientras que las cosas "son”, la conciencia siempre es más de lo que es, contiene en sí un futuro de proyectos que sólo se cancela con la muerte. La falta moral o "mala fe" consistirá en ignorar deliberadamente esa estructura propia que nos condena a la libertad y renegar de esta última, como si nuestro ser tuviera el carácter predeterminado de las cosas. Corresponde apuntar que, en esta gran división ontológica, los animales no humanos quedaban del lado de las cosas. Eran meros cuerpos, ya que ni Sartre ni Beauvoir les concedían conciencia (Puleo, 2011). Volveré más adelante sobre esta extraña visión que, a pesar de su evidente incapacidad de captar la particular realidad de los animales no humanos, sigue siendo hegemónica y se hace patente en la indiferencia ante el tratamiento violento que reciben. Esta inclusión de los animales no humanos en el registro de las cosas, sujetas, por tanto, a la apropiación, es la base de la legislación de la totalidad de los países, si bien es cierto que actualmente se están produciendo algunos pequeños cambios alentadores.

En su elaboración de las tesis de la intencionalidad de la conciencia de Husserl y de la categoría de Otro hegeliana ${ }^{1}$, Beauvoir mantendrá que a las mujeres se les impedía realizarse como seres humanos plenos al eliminar sus posibilidades de elección de un proyecto de vida. "lo que define de forma singular la situación de la mujer es que, siendo como todo ser humano una libertad autónoma, se descubre y se elige en un mundo en el que los hombres le imponen que se asuma como la Alteridad, se pretende petrificarla

1 Teresa López Pardina ha subrayado la diferencia que separa la noción de "situación” de Beauvoir con respecto a la de Sartre. En Beauvoir, la situación delimita la libertad, mientras que en Sartre nunca constituye un obstáculo para la libertad (López Pardina, 1998). 
como objeto, condenarla a la inmanencia” (...) (Beauvoir, 1998:63). La sociedad de los años cuarenta reconocía sólo dos roles principales al colectivo femenino (o Madre o Prostituta) con lo que dejaba en su mínima expresión la posibilidad de desarrollo en el ámbito de la libertad de todas y cada una de las mujeres.

El acierto de Beauvoir consistirá en exigir el reconocimiento de las mujeres como seres para sí a las que, en tanto humanos caracterizados como libertad que se desarrolla en un proyecto existencial, han de tener las mismas posibilidades de elección de los varones (López Pardina, 1998). La subordinación del "segundo sexo" consistía en el hecho de que se le negaba la posibilidad de construirse como sujetos, reduciéndosele, así, al rango de las cosas. La maternidad como destino debería convertirse, pues, en maternidad como proyecto libre, lo cual exigía dejar atrás la maternidad forzada y ofrecer a las mujeres la participación en el mundo de la Cultura, pero no sólo proveyéndolas de unas nociones básicas que les permitieran admirar el mérito de los hombres ilustres, como proponían tantas guías educativas desde el Renacimiento. Las mujeres ya no aceptarían sus papeles pre-establecidos de musas inspiradoras, cuerpos para el placer y reproductoras de la especie. Serían sujetos de pleno derecho en el ámbito de la cultura, del trabajo asalariado, de la política y de todos los aspectos del mundo de lo público.

Recordaba al comienzo de estas líneas que las feministas de la segunda ola del siglo XX se movilizaron con el lema "El feminismo es la idea radical de que las mujeres son personas". Con estas palabras, las autodenominadas "hijas de Beauvoir" definían la doctrina que las inspiraba. Rechazaban, de esta manera, la tradicional reducción de las mujeres a cuerpos que nutren o que se exhiben para placer de los demás. La etimología de persona aclara lo que encierra este concepto y lo que significa ser excluido/a de su aplicación. El término griego $\pi \rho o ́ \sigma \omega \pi o v$ remite a la máscara que usaban los actores en el teatro clásico para que su voz pudiera ser oída en las gradas más alejadas del escenario. Persona es quien hace sonar su voz, quien más allá del mero cuerpo tiene una vida mental que ha de ser reconocida, alguien con intereses propios que han de ser tenidos en cuenta. Persona es alguien que no es un mero medio, alguien que no es sólo para otros. Una persona no se agota en su valor instrumental para otros individuos.

Detengámonos un instante en un pensador clave de la filosofía occidental: Aristóteles. El Estagirita subraya que sólo los humanos poseen la palabra y fundamenta la jerarquía consagrada por la sociedad griega entre libres y esclavos en la misma teleología de la Naturaleza: "el que es capaz de previsión con su inteligencia es un gobernante por naturaleza y un jefe natural. En cambio, el que es capaz de realizar las cosas con su cuerpo es súbdito y esclavo, también por naturaleza. Por tal razón, amo y esclavo tienen una conveniencia común.” (Aristóteles, Libro I, Capítulo 2, 1252a 3943). La supuesta posesión de un mayor grado de razón legitima al amo en su dominio sobre el bárbaro. El primero puede servirse de la mente, el segundo, de su cuerpo. La sabia Naturaleza habría dispuesto que estos cuerpos recibieran su finalidad de las conciencias libres. Por ello, concluye en el capítulo quinto que la esclavitud es justa. En el VIII, apela al telos de la Naturaleza para demostrar que los animales, divididos en domésticos y salvajes, existen para utilidad del hombre ya que la Naturaleza "no 
hace nada imperfecto ni en vano" (Aristóteles, I, 1256b 27). De ellos se obtiene alimento, vestido y otros utensilios. Resulta sumamente interesante que, al referirse a la caza de los animales salvajes, la define como "arte adquisitivo" y "arte de la guerra”. Y añade que la caza como arte adquisitivo de la guerra es tanto la que se libra contra los animales como la que se hace a "aquellos hombres que, si bien han nacido para ser gobernados, se niegan a ello" (Aristóteles, I, 1256b 32-34). Sabido es que las guerras contra los pueblos bárbaros proveían a los griegos de mano de obra esclava. Pero adelantémonos a quienes dirán que en la época de Aristóteles no se podía pensar de otra manera. El mismo Aristóteles se refiere claramente a la existencia de tesis que negaban el carácter natural de la esclavitud (Libros III y VI). En realidad, un talante conservador le llevó a posicionarse contra las corrientes sofísticas que criticaban la esclavitud como contraria a la physis y a reafirmar el lugar tradicional de las mujeres frente a cualquier veleidad emancipatoria. Ahora bien, se le puede calificar de sexista pero no de misógino (Femenías, 1996). No le mueve el odio o la animadversión. Defiende, desde la filosofía, simplemente, el orden jerárquico de su sociedad de acuerdo a una gradación descendente de la capacidad del espíritu para controlar el cuerpo propio. Esta escala va desde los animales silvestres (el nivel más bajo) hasta el varón griego (el más alto). El buen gobierno de la polis requiere casas ordenadas racionalmente y esclavos y esposas bien dispuestos para sus labores, por lo tanto, recomienda dar un buen trato a mujeres y esclavos. Con ello, involuntariamente, deja testimonio de la existencia de violencia cotidiana hacia los sometidos como la cara oculta de su pretendida armonía del oikos.

En el caso de las mujeres, advierte, la unión con el varón tiene finalidad reproductora. Aristóteles adhería a la teoría monoseminal según la cual las mujeres eran las vasijas nutrientes pasivas que recibían la semilla para que ésta desarrollase sus potencialidades. El hombre aportaba la forma y la mujer la materia (Femenías, 2002). Vemos, pues, que de una u otra manera, en distintos rangos y formas, los individuos que son eminentemente cuerpos, "son para” el hombre libre, que está definido por lo que le caracterizaría específicamente: el pensamiento. Mujeres, esclavos y animales son lo Otro de lo Uno. Son definidos por la carencia de aquello considerado superior: el intelecto, el espíritu.

Es indudable que para comprender en profundidad el entramado patriarcal y su historia hemos de atender a los dualismos jerarquizados que lo estructuran y que descansan, en última instancia, en la oposición Uno/Otro probablemente desde los albores de la hominización ${ }^{2}$. Incluso en una tradición holista como la védica, ajena a la tajante división occidental entre materia y espíritu ${ }^{3}$, éste (Purusha) es concebido como masculino frente a la materia y a la Naturaleza (Prakriti), imaginadas como femeninas.

2 El dimorfismo de nuestra especie parece refutar la hipótesis de un matriarcado primigenio. Son dimórficas aquellas especies en que el macho y la hembra se distinguen claramente a la vista sin tener que examinar sus órganos sexuales.

3 "En la cosmología india persona y naturaleza (Purusha-Prakriti) son una dualidad en la unidad. Son complementos inseparables en la naturaleza, en la mujer y en el hombre” (Shiva, 1995: 79). 
Que las mujeres son personas, que son cuerpos con conciencia en igual medida que los varones, que son individuos y no miembros de un todo indiferenciado, es una afirmación que ha marcado el rumbo de gran parte de la lucha feminista. Como ha señalado Cèlia Amorós, puesto que la individualidad es una categoría política y ontológica, ser percibida como idéntica significa ocupar espacios simbólicos en los que "se hace irrelevante la determinación de la individualidad: no hay razón suficiente para que la atención se tome la molestia de realzarla, sino que queda subsumida en la indiscernibilidad, bajo predicaciones que afectan indistintamente a todos los ejemplares pertenecientes al genérico" (Amorós, 1997: 211). La desindividualización o proceso de borrado de las características individuales de los miembros del grupo oprimido se encuentra en estrecha relación con su cosificación. Las mujeres lo han sufrido de manera intensa, quedando sujetas a definiciones generalizantes provistas por los estereotipos de género.

Reivindicar el estatus de persona es, efecto, una idea "radical”, ya que va a la raíz misma de la alienación y de la dominación secular sufrida por el "segundo sexo". No era otra la exhortación que Mary Wollstonecraft dirigía a sus contemporáneas: debían reivindicar su dignidad de personas, ya que creer en el poder de la belleza era sinónimo de convertirse en esclavas o en déspotas, renunciando a sus capacidades naturales y al respeto que inspiran la autonomía y la fortaleza de carácter. Esta rousseauniana feminista las comparaba a pájaros cautivos, “confinadas en jaulas", entregando "salud, libertad y virtud" (Wollstonecraft, 1994: 183) a cambio de comodidades y atenciones insignificantes que pronto dejan traslucir el desprecio. $\mathrm{Ni}$ siquiera las aspiraciones de universalidad ética de Kant pudieron superar la rebaja de sus asunciones antropológicas que eran las de la mayoría de pensadores ilustrados (Roldán, 2013; Posada Kubissa, 2012). Las mujeres no accederían a la plena ciudadanía de la Modernidad debido a la supuesta debilidad de su juicio moral. Eran "el bello sexo" determinado por su cuerpo y sus funciones reproductoras. Estas convicciones kantianas pervivirán en la teoría freudiana. La internalización de los valores y la formación del superyó a través del miedo a la castración, sostendrá el creador del psicoanálisis, se da correctamente en los varones, las mujeres sólo desarrollan una apariencia de moral sin principios sólidos. En la historia del pensamiento, encontramos, implícita o explícitamente, con escasas y honrosas excepciones, una misma idea: las mujeres no acceden plenamente al nivel de conciencia e individualidad que caracteriza a la excelencia humana. Amelia Valcárcel subrayará que sólo a través de la formación de un "nosotras" se puede vencer este mecanismo de esencialización que niega la individualidad de cada mujer: "Paradójicamente construir la individualidad no es una tarea individual, sino colectiva” (Valcárcel, 1997:80). Es una tarea colectiva, ética y política. Es la tarea del feminismo, porque el reconocimiento de la individualidad depende, como hemos visto, de las relaciones de poder en juego.

\section{VIOLENCIAS PATRIARCALES}

La violencia es, estadísticamente, un fenómeno de autoría abrumadoramente masculina. Sin embargo, casi nunca se recuerda este hecho. Quien lo señale, corre el grave riesgo de cargar con el estigma del esencialismo. Excepto cuando se trata de referirse específicamente a la violencia contra las mujeres, se suele hablar de los actos violentos como si estuvieran equilibradamente repartidos entre hombres y mujeres y fueran de género neutro, como algo simplemente "humano" (Miedzian, 1995). No 
sostengo la existencia de una esencia masculina independiente de la sociedad patriarcal. Hay mujeres violentas y varones pacíficos. Pero los porcentajes según el sexo son muy distintos. Al igual que en la cuasi-totalidad de las generalizaciones de las ciencias sociales, afirmar que la violencia se da sobre todo en los varones es un enunciado que admite diferencias individuales y contextuales pero que se apoya en una base estadísticamente relevante. Como señala Amelia Valcárcel, en el ámbito de la fratría como grupo viril de educación informal "ser varón es asumir que la violencia es ratio y, a veces, ultima ratio ${ }^{4}$ (Valcárcel, 2008:262).

El concepto de género como construcción sociocultural e histórica de las diferencias entre los sexos (Puleo, 2013) ha permitido analizar la construcción del modelo tradicional del guerrero y sus variantes contemporáneas. La iniciación a la masculinidad estereotipada siempre incluye un elemento de violencia. Como sugiere con profundidad, finura y gran elocuencia la película In the Valley of Elah ${ }^{5}$, existen vínculos subterráneos, por lo común desapercibidos, entre la violencia contra las mujeres y contra los animales, las prácticas sádicas y la socialización masculina para la guerra. En su estudio de finales del siglo XX sobre la violencia masculina en USA, la psicóloga social Myriam Miedzian desvelaba que instructores militares de su país animaban a los aspirantes a entrar en la institución a "matar la mujer que tienen dentro”, obligándoles a matar, para demostrar que lo habían logrado, a un cachorrillo de perro que habían tenido que cuidar durante los meses de entrenamiento; también mostraba que en los círculos diplomáticos y políticos, las actitudes conciliadoras que buscaban evitar el enfrentamiento armado eran vistas como poco viriles, como “afeminadas" (Miedzian, 1995).

Los animales no humanos sirven, a menudo, de medio para la construcción de una identidad viril concebida históricamente como separación con respecto a los sentimientos de empatía y compasión por el Otro. Pensemos, por ejemplo, en la tortura y muerte de animales como diversión de la pandilla de niños o adolescentes, o en la caza deportiva que podemos definir como guerra sistemática declarada a los animales silvestres por individuos generalmente de sexo masculino. En la actualidad, las redes sociales son una ventana abierta a esta violencia desatada contra los animales, tanto para mal (individuos que cuelgan los videos sádicos que han grabado o las fotos de sus supuestas hazañas) como para bien (campañas de denuncia y peticiones de castigo judicial de los abusos). Esta violencia contra criaturas indefensas tiene dos objetivos fundamentales: experimentar la voluntad de poder y afirmar y solicitar el reconocimiento de su identidad de género bipolarizada obtenida por la represión de los sentimientos de compasión. El "duro" es un resultado de técnicas de género

\footnotetext{
${ }^{4}$ Particularmente interesante es la explicación que da A. Valcárcel sobre una nueva forma de violencia que soportan las jóvenes sin identificarla como abuso: la violencia entre los "iguales" que en realidad físicamente no lo son: "una igualdad mal asumida por el conjunto puede dar lugar a una violencia nueva” (Valcárcel, 2008:271).

5 Estrenada en el año 2007, dirigida por Paul Haggis y protagonizada por Tommy Lee Jones, Susan Sarandon y Charlize Theron, fue proyectada con tres títulos distintos en países de habla castellana: En el valle de Elah, Valle de las sombras y La conspiración.
} 
específicas que proceden a extirpar características previamente definidas como propias del sexo femenino. La construcción del héroe es una peligrosa empresa que no siempre resulta exitosa y puede fácilmente producir villanos.

En esta lógica patriarcal, la mujer aparece como figura caracterizada por la emocionalidad y la debilidad de la que hay que diferenciarse para ser superior, inconmovible e imperturbable. Debemos recordar que, tradicionalmente, al colectivo femenino se le ha prohibido el acceso a las armas. Esta exclusión ha funcionado como incentivo para las actividades violentas de algunos varones ya que el hombre, concebido como protector (guerrero, cazador, torero... frente al enemigo, al animal, al “monstruo”...), podía esperar el premio de la admiración y el amor femeninos ${ }^{6}$. La socialización de género no es asunto del pasado. Como observa Ana de Miguel, la conjunción de patriarcado y capitalismo abre nuevas vías de troquelado de la identidad de género: "En la actualidad las normas de la diferencia sexual no se difunden desde la ley ni desde el estado, ni desde la educación formal. Se forjan desde el mundo de la creación, en la música, los videoclips, el cine, las series, la publicidad... se difunden desde los medios de comunicación de masas y generan unas poderosas industrias que ofrecen un consumo diferenciado para chicas y chicos. Para ellas el culto a la imagen, al cotilleo y al amor romántico. Para ellos la tríada fútbol-motor-pornografía.” (De Miguel, 2008 a:36).

Algunos pocos filósofos han afirmado que la violencia y la crueldad estaban inscritas en la naturaleza misma del varón y lejos de considerarlas un aspecto a erradicar o una desviación del ideal humano, hicieron de ella su realización más elevada. Me estoy refiriendo en particular al marqués de Sade y a Georges Bataille, que sostuvieron que la tendencia a la dominación y a la destrucción estaba inextricablemente unida al deseo sexual. Ambos oscilan _sobre todo Sade_entre considerarla una tendencia innata masculina o una pulsión humana general. Pero en algunos pasajes clave, incluso Sade deja entrever una división de género. Afirma el autor que los surrealistas denominaron "Divino Marqués" que la estabilidad de una república depende de la libertad con que se permita la expresión de los deseos sexuales del hombre entre los que se cuentan "la sodomía, las fantasías sacrílegas y los gustos crueles” (Sade, 1999:76). La pasión de la lujuria, sostiene, implica el placer de mandar, de esclavizar. Por ello, "siempre que privéis al hombre del medio secreto para que exhale la dosis de despotismo que la naturaleza ha puesto en el fondo de su corazón, no vacilará en ejercerlo sobre los objetos que lo rodean, perturbará el gobierno" (Sade, 1999:149).

En la contrastación entre Rousseau y Sade podemos encontrar claramente conceptualizadas las dos figuras principales en que el patriarcado despliega su concepción de la feminidad que Luisa Posada Kubissa expresó con un título ingenioso

\footnotetext{
${ }^{6}$ No sólo hay una continuidad sino un movimiento de reacción que he llamado "Contrarreforma Patriarcal”. Para un ejemplo sencillo, basta ver Jurassic World (2015), cuarta película de la serie Parque Jurásico que podemos resumir así: Hombre valeroso y auténtico logra recordar a fría mujer del neoliberalismo cuál es la verdadera naturaleza femenina. Lo único nuevo es la tecnología 3D.
} 
e incisivo: "Un Gran Reserva francés frente al vino de mesa rousseauniano" (Posada Kubissa, 1994): la madre y la prostituta. Mientras que el burgués "parvenu” negará la ciudadanía a las mujeres porque las destina exclusivamente a la crianza de los futuros ciudadanos, el aristócrata libertino propondrá la propiedad en común de las mujeres para el placer. La igualdad republicana ha de seguir las sabias leyes de la Naturaleza que, a su juicio indican que "ningún hombre puede ser excluido de la posesión de una mujer, desde el momento en que es evidente que ésta pertenece a todos los hombres" Sade,1999:151). Pero a continuación aclara que, en tanto ser humano, la mujer no puede ser de un acto de apropiación ya que, a su juicio, éste solamente puede tener lugar sobre un inmueble o un animal. Por ello, añade:

"tenemos el derecho de obligarlas a que se sometan a nuestros deseos, no en forma exclusiva, porque de ese modo caería en contradicción, sino de manera momentánea" (...) "repito que se trata aquí del goce y no de la propiedad, no tengo ningún derecho a la propiedad de esta fuente que encuentro en mi camino, pero tengo derechos ciertos para disfrutar de ella, tengo derecho a aprovecharme del agua límpida que ofrece a mi sed, de la misma manera, no tengo ningún derecho real a la propiedad de tal o cual mujer, pero sí lo tengo innegablemente a gozar de ella, lo tengo de obligarla a tal goce si me lo niega por cualquier motivo que sea" (Sade, 1999:152).

Según Bataille, pensador fuertemente influenciado por el pensamiento de Sade, los revolucionarios de 1789 introdujeron un orden en el que el acto de la "révolte" queda excluido como irracional. A partir de ese momento, sostiene, todo quedará subordinado a la necesidad y a la utilidad. Una vez ejecutado el rey, en esa nueva sociedad de los iguales ni siquiera se dispondrá de una figura que represente al hombre soberano, al ser que no puede ser confundido con una cosa. Pero, afirma el autor de $L a$ souveraineté, la experiencia de la soberanía es imprescindible y pertenece a la esencia del hombre, por lo que retornará una y otra vez como lo reprimido, lo hará en el fenómeno de las guerras. La virilidad ha de luchar contra la mesura, lo útil, el justo medio, lo sano y lo limpio. Estos valores "burgueses" impiden la vivencia de la soberanía. Bataille retoma la idea de Blanchot de que el sádico encierra la verdad del hombre normal: «l'impulsion de l'homme souverain fait de lui un meurtrier. La mort est la négation illimitée du monde de la pratique » (Bataille, 1986 : 515). El abandono del mundo puro que el hombre había construido gracias a las prohibiciones y las reglas permite experimentar la voluptuosidad del mal que está ligada al vértigo de la caída y de la acción gratuita. ¡Qué conocido nos es este elogio de la transgresión! ¡Cuántos lo han recogido en sus escritos y declaraciones!

No resulta sorprendente que, a la hora de tratar la teoría del erotismo, Georges Bataille sea el maestro ineludible, se nombre o no. Cierto es que no abundan las incursiones sobre la sexualidad en la historia de la filosofía, pero no es esta la única razón de su éxito. El erotismo como sacrificio ritual y el deseo como voluntad de aniquilación o negación de los límites del ser determinado, es decir, de los cuerpos, alcanzan su pleno desarrollo en este intérprete de Sade que, a diferencia del maestro, 
se limita a una propuesta heterosexual. Según su interpretación, en el encuentro erótico el amante es el "sacrificador sangriento" y la mujer el "animal inmolado" que pierde, así, la individualidad para ingresar en la unidad indiferenciada e irracional del ser. El entusiasmo que ha suscitado esta teoría en numerosos intelectuales revela que ha sabido expresar en el plano del concepto las vivencias de la sexualidad de gran cantidad de individuos socializados en la cultura patriarcal. Por eso creo que vale la pena recordar su teoría de la diferencia entre sexualidad y erotismo.

Para Bataille, la sexualidad sería propia del animal en su inocencia impulsiva y libre. El erotismo, en cambio, sería el producto cultural que nos haría propiamente humanos. Habría surgido de la imposición de prohibiciones y normas. Estas demarcaron un territorio de lo sagrado, de lo puro y espiritual, creando como su opuesto, un espacio de fango y abyección. El rechazo a la Naturaleza, afirma, proviene del deseo de olvidar lo que es vulnerable en nosotros mismos, es decir, la carne, y elevarse por encima de las necesidades animales a través de lo espiritual. Sólo este segundo momento, afirma, correspondería al paso de lo animal a lo humano. En él se construirá ese objeto simbólico que es la feminidad. El establecimiento del tabú del incesto $^{7}$ y las normas de distribución de las mujeres a través del matrimonio exogámico estudiadas por Lévi-Strauss configuran el orden que posibilitará, justamente, la aparición de un tercer momento dialéctico o negación de la negación. Si la primera negación era rechazo de la naturaleza, de la desnudez de los cuerpos animales, la segunda negación es negación de esta negación, es decir, negación de las normas a través de su transgresión, Surgiría así el erotismo como experiencia de éxtasis y de soberanía inextricablemente ligado a la muerte. Se volvería a la Naturaleza pero no a la originaria sino a una naturaleza maldita, mediada por las prohibiciones y el sentimiento de corrupción y pérdida. Para Bataille, el objeto erótico por excelencia es la prostituta: “L'attrait de la nudité n'est pas le lot des seules prostituées mais c'est l'attrait d'une chose, d'un objet sasissable, et l'amour vénal a le privilège de réduire une femme à cet « objet » qu'est la nudité érotique » (Bataille, 1976:122). Su cuerpo no presenta la franca desnudez preconizada por el naturismo. Por el contrario, conserva algunos restos de ropa que recuerdan la norma quebrantada, evocan la falta, la vergüenza y el estigma de la civilización. En tanto suspensión excepcional de la prohibición, la transgresión soberana necesita la permanencia de las normas y solo es posible gracias a ellas. Enemigo de una revolución sexual que las aboliera, Bataille se indignó ante los informes Kinsey que describían y clasificaban los actos sexuales despojados de la dimensión trágica, metafísica y sagrada que él les había concedido (Bataille, 1976).

Para este filósofo de la transgresión, el deseo de perderse y perder sería la manifestación de lo propiamente humano negado por el nuevo orden burgués. Por ello, sostiene que salvar la civilización y lograr que desaparezcan las guerras, sólo se logrará a través de dos medidas: reducir la desigualdad económica que separa los distintos niveles sociales y dar mayor lugar al erotismo de manera que se canalicen las energías

\footnotetext{
${ }^{7}$ Gracias a estudios de etología inexistentes en la época de Bataille, hoy sabemos que el tabú del incesto ya existe entre los primates superiores y que, por lo tanto, no es un fenómeno exclusivamente humano.
} 
destructivas excedentes, "la parte maldita". La verdad del erotismo residiría, a su juicio, en la experiencia violenta de mancillar y destruir la belleza, la pureza, el orden y las normas establecidas. El deseo sólo podría cumplirse plenamente en la forma perversa de la aniquilación del objeto deseado. Por eso compara el acto sexual con los antiguos sacrificios humanos o de animales y se siente fascinado por las corridas de toros. Frente a la acumulación paciente y esforzada del mundo profano del trabajo, la "fiesta", el sacrificio ritual y el erotismo serían actos gratuitos de pura pérdida en los que el hombre recuperaría momentáneamente la experiencia de la soberanía al transgredir y destruir los límites del cuerpo deseado. Serían actos sagrados porque no están dictados por la utilidad, son puro exceso, gratuidad, trascendencia hacia la libertad. Las mujeres y los animales, reconoce, son los objetos privilegiados del sacrificio.

Consideremos ahora nuevamente el concepto de persona. El estatuto de persona es un salvoconducto frente a la explotación y a la dominación. Si bien la noción de persona es muy "elástica” y su aplicación depende a menudo de intereses económicos hasta el punto de que los esclavos en EEUU eran reconocidos como seres humanos pero no como personas, los atributos que actualmente la Bioética considera propios de alguien a quien se puede denominar persona son, nos recuerda Gary Francione: "un mínimo de inteligencia, de autoconciencia, de autocontrol, un cierto sentido del tiempo, un sentido del futuro, un sentido del pasado, la capacidad de relacionarse con otros, la preocupación por otros, la comunicación, el control de la existencia, la curiosidad, el cambio y la variabilidad, el equilibrio entre racionalidad y sentimiento, la idiosincrasia y el funcionamiento neo-cortical” (Francione, 1998:315). Los grandes simios cumplen estos requisitos ${ }^{8}$. Y aún para aquellos animales muy simples que no lo hicieran, cada vez más numerosos son las y los pensadores que reclaman su admisión en el círculo de nuestra consideración moral en base a su sensibilidad. Los animales no humanos no son cosas. Son, en palabras de Asunción Herrera Guevara, "mi otro significativo” (Herrera Guevara, 2014) y así serán reconocidos en la que espera sea la “Tercera Ilustración” que traería la justicia interespecífica.

La cosificación es el primer paso hacia la dominación, la explotación y la violencia extrema. Viendo esta correlación en sentido inverso, puede decirse que cuando existen intensos procesos de explotación y dominación, se ponen en marcha mecanismos legitimantes de cosificación. La Historia y la Sociología nos muestran que la cosificación permite que se instale la explotación sistemática y se desarrollen las prácticas sádicas. Schopenhauer, filósofo misógino, afirmó que los hombres habían hecho de la Tierra un infierno para los animales. El feminismo ha mostrado que innumerables mujeres han sufrido y sufren durísimas situaciones de dominación y explotación. El sexismo y el especismo tienen un gran parecido de familia. Así lo vieron algunas sufragistas antes de que se forjaran estos términos (Rodríguez Carreño, 2012; Bianchi, 2015), así lo vemos hoy algunas ecofeministas al pensar a los animales no sólo en términos de especie sino de individuos que sufren, que piensan, que

${ }^{8}$ Por lo que recientemente tribunales de distintos países han solicitado para ellos el habeas corpus que pondría fin a su encarcelamiento de por vida en una jaula. 
esperan... (Adams \& Donovan, 1995; Puleo, 2011). Un video terrible que no consigo olvidar mostraba una escena de lapidación real de una mujer. La excitación de la turba, el placer de su ensañamiento y la terrible soledad final de la víctima rodeada de sus verdugos trajeron a mi mente, como un espejo fragmentado y multiplicado al infinito, las masacres públicas de aterrorizados animales en abominables fiestas populares del mundo hispánico. El patriarcado mata de muchas maneras.

En su rechazo de la Modernidad, Bataille reclamaba los privilegios de la soberanía patriarcal del pasado. En efecto, podemos decir que la Ilustración civilizó la sociedad occidental al exigir que todas las tradiciones se presentaran, según la elocuente metáfora de Kant, ante el tribunal de la razón. Los actos que implicaran infligir sufrimiento tuvieron que ser justificados con motivos de utilidad, fundamentalmente alimentaria o de investigación médica. La figura del científico imperturbable ante la mesa de vivisección sería un nuevo modelo de masculinidad, el "testigo modesto" de Donna Haraway (2004). Se limitó todo lo posible la exhibición pública de escenas de violencia y, con mucho esfuerzo, se consiguió que se dictaran leyes para castigar y prevenir la crueldad contra los animales. Las diversiones populares basadas en la tortura y la muerte sólo continuaron existiendo en aquellos países en los que la Ilustración se había encontrado con la resistencia de poderosas fuerzas oscurantistas.

El ocultamiento de las escenas de violencia real educó a la ciudadanía desarrollando su sensibilidad y su tendencia a rechazar el ejercicio de la crueldad. Hace unos años, Paul McCartney afirmó que si los muros de los mataderos fueran de cristal, el mundo sería vegetariano. No sé si me atrevería a generalizar tanto pero, desde luego, es cierto que nuestra sensibilidad ha sido educada en este proceso ilustrado. Por ello, hoy, incluso la violencia real con fines utilitarios se oculta a través de una serie de distorsiones defensivas. Como señala Melanie Joy, frente a la insoportable dureza de la realidad de la explotación de la industria de la carne y su inaceptabilidad moral: "La tríada cognitiva comprende la cosificación, la desindividualización y la dicotomización (Joy, 2013: 121). Estos mecanismos son comunes a todos los procesos de dominación y explotación masivas y pueden ejemplificarse con los campos de concentración del nazismo. En el caso de los animales no humanos, la cosificación no sólo se expresa en el lenguaje sino en las leyes de todos los países. Alemania, Francia y Nueva Zelanda ${ }^{9}$ han reconocido sólo recientemente a los animales no humanos un estatuto de seres con capacidad de sentir. Pero siguen siendo objetos de propiedad. El Código Civil español, aprobado en 1889, los considera cosas, "seres semovientes” (del latín se movens-entis, entes que son capaces de moverse por sí mismos). Adelantándose a la tesis del animal máquina de Descartes, el médico y filósofo español Gómez Pereira, sostuvo que los animales no sólo no eran capaces de hablar, sino que tampoco podían moverse por sí mismos ni experimentar sufrimientos (Romero, 2015). M. Joy observa que en la actual industria cárnica los animales son llamados “unidades”. El lenguaje cosificador y la sustitución del nombre por el número facilita la tarea de los matarifes, ayudándoles a olvidar que están destruyendo cuerpos con mentes, seres con sentimientos,

\footnotetext{
${ }^{9}$ Para el caso de este último país, ver The Independent, 7 June, 2015.
} 
pensamientos y una memoria que permite la existencia de su identidad única en el tiempo.

Esta violencia de la explotación no termina de desplazar la antigua violencia de la soberanía. En el ámbito oculto de los mataderos, en esos espacios de muerte que preferimos ignorar, se desencadenan también actos de sadismo. Escenas atroces de violencia gratuita e inexplicable son allí fenómenos comunes (Joy, 2013). A menudo se acompañan de obscenidades e insultos sexistas. El sadismo es un reconocimiento implícito de que esos seres condenados no son ni cosas ni números, que son conciencias sufrientes que interpelan con la mirada a sus torturadores pidiendo compasión.

En su alabanza de las fiestas y ceremonias sangrientas, Bataille llega cínicamente a afirmar que la violencia ejercida sobre el ser sacrificado lo libera del mundo profano y lo convierte en sagrado. La inmolación eliminaría sus límites, devolviéndolo a la totalidad $^{10}$. La realidad es muy distinta. Sostengo que la violencia y el sadismo constituyen un reconocimiento perverso de la individualidad devaluada que procede a su negación final. Como una infección oportunista, la violencia y el sadismo eligen como víctimas a quienes no se les había concedido pleno valor intrínseco.

El feminismo ha denunciado estos mecanismos en su aplicación a las mujeres. Quien cae bajo la definición de ser-para-otros es blanco privilegiado de la violencia sádica. Las víctimas de la explotación corren grave riesgo de caer en manos sádicas porque, en su caso, la sociedad ya ha procedido a una devaluación y, por lo tanto, es más indiferente y permisiva con los verdugos. Suele mirar hacia otro lado. Sabido es, por ejemplo, que el feminicidio en la frontera mexicana se alimenta con jóvenes trabajadoras de las maquilas y que los autores de sus salvajes muertes permanecen desconocidos e impunes. Que las jóvenes violadas colectivamente y asesinadas en Ciudad Juárez sean mordidas y despedazadas es altamente significativo. Analizando este dato escalofriante, Celia Amorós ha relacionado "la obsesión por el descuartizamiento del cuerpo femenino con la ausencia de individuación que presentan las mujeres en el imaginario patriarcal” (Amorós, 2008: 300) y ha sugerido que estos asesinatos implican un simbolismo que remite al "imaginario libertino" de transgresión de la ley del Padre (Amorós, 2008:279), lo cual nos devuelve a la teoría sadobatailleana que hemos estado examinando.

Subrayar la relación entre cosificación y violencia no significa ignorar otros elementos contextuales. Algunas teóricas latinoamericanas que han reflexionado sobre el incremento de la violencia contra las mujeres han identificado distintos factores clave. Marcela Lagarde creó el término "feminicidio" para referirse tanto a asesinatos producidos en el ámbito de la pareja como a los llevados a cabo por bandas armadas. Lo define como crimen de Estado por la responsabilidad de las instituciones políticas patriarcales que practican la dejación sistemática, favoreciendo la impunidad. Observa que el sustrato que los hace posibles es la desigualdad estructural que afecta a las

\footnotetext{
10 Esta afirmación tiene la misma "lógica” que la de toreros y aficionados que sostienen que en la plaza el toro es respetado en su grandeza.
} 
mujeres y la ideología de la misoginia (Lagarde, 2008). Ante el recrudecimiento de la violencia cotidiana contra las mujeres, María Luisa Femenías ha avanzado la hipótesis de que se trataría de una "restauración fallida" del orden patriarcal tradicional que se ve amenazado por los cambios inherentes al capitalismo globalizado" ${ }^{11}$ : $\mathrm{Si}$ los varones hegemónicos subalternizan a los varones feminizados, éstos a su vez, se autoinstituyen en subalternizadores del colectivo de mujeres a fin de restituir un orden jerárquico natural anacrónico ontologizado" (Femenías, 2013: 134). Por su parte, en el análisis de los crímenes de Ciudad Juárez y otros casos similares, Rita Segato ha subrayado que "el cuerpo femenino o feminizado" 12 , cumple la función de mensaje de soberanía territorial entre los grupos armados enfrentados porque el cuerpo de las mujeres siempre ha poseído un significado territorial, como lo prueban las tradicionales violaciones en las conquistas bélicas. Nos encontraríamos así, ante nuevas formas de guerra que asumen como estrategia premeditada lo que antes eran efectos colaterales y condenados de la acción bélica (Segato, 2013). Me gustaría señalar que el cadáver de los animales no humanos es utilizado comúnmente como signo de advertencia y amenaza. Desde el uso rutinario de la violencia contra los animales de compañía por parte de los maltratadores, pasando por las malas relaciones de vecindad, hasta las prácticas del grupo guerrillero peruano Sendero Luminoso en 1980, cuando, entre otras acciones similares, dejó decenas de perros colgados de las farolas del centro de Lima, existe un amplio abanico de casos en que el cuerpo animal es convertido un mensaje de soberanía, intimidación y dominio.

\section{MÁS ALLÁ DE UNA CULTURA DE LA DOMINACIÓN}

En estas líneas he buscado el trasfondo común de las violencias patriarcales. Lo he hecho desde la convicción de que un futuro diferente ya está en marcha. Señala Ana de Miguel que una de las contribuciones más relevantes que pueden hacer los movimientos sociales es "el proceso por el que un colectivo social llega a definir como injusto y objeto de cambio social una situación generalmente legitimada por la tradición cultural, la costumbre -y como diría Burke_- la duración” (De Miguel, 2008b:130). El feminismo nos enseñó a pensar como política una opresión que parecía

\footnotetext{
11 (en un contexto de) “creciente número de varones inferiorizados por razones económicas que quedan fagocitados en un complejo fenómeno de feminización” (...) “los varones _ a partir de los cambios del mercado laboral y de la cultura en general_, estarían intentando con mayor ahínco disciplinar con violencia a aquellas mujeres “autónomas” que ven como el eje de sus males” (Femenías, 2013:44).

12 "Es muy importante aquí hacer notar otra importante característica de este nuevo escenario de guerra: ese cuerpo en el que se ve encarnado el país enemigo, su territorio, el cuerpo femenino o feminizado, generalmente de mujeres o de niños y jóvenes varones, no es el cuerpo del soldado-sicario-mercenario, es decir, no es el sujeto activo de la corporación armada enemiga, no es el antagonista propiamente bélico, no es aquél contra quien se lucha, sino un tercero, una víctima sacrificial, un mensajero en el que se significa, se inscribe el mensaje de soberanía dirigido al antagonista.” (Segato, 2013:60-61)
} 
natural. Continúa hoy teniendo entre sus objetivos la lucha por la desnaturalización de la violencia contra las mujeres, una lucha exitosa pero aún lejos de estar totalmente ganada. El movimiento por la defensa de los animales tiene una tarea aún más difícil. La situación de los animales no humanos es la peor de todas las épocas desde que comparten el planeta con el anthropos. Por un lado, la crisis ecológica generada por el modelo devastador de desarrollo pone a la fauna silvestre al borde de la extinción. Por otro, se ha construido un sistema monstruoso de campos de exterminio en el que millones de animales destinados al consumo o a la experimentación son privados de toda libertad y sometidos a atroces sufrimientos hasta la muerte. Sin embargo, cada vez son más los jóvenes que adhieren a la causa animalista _que cuenta con numerosas activistas mujeres_desde la publicación, a mediados de los años setenta del siglo XX, del libro Animal Liberation del filósofo australiano Peter Singer. Se trata de un tema clave de nuestro tiempo, un tiempo en el que Occidente comienza a descubrir el parentesco que nos une a todos los animales, humanos y no humanos, cuerpos con mentes, con conciencia y sentimientos, sujetos de una vida. Porque, sin ninguna duda, estamos tomando conciencia del "continuum que, como han mostrado magistralmente la etología y otras ciencias, compartimos con los otros animales, prójimos y próximos, animales no humanos entre animales humanos” (Ausín y Rodríguez Carreño, 2012:8).

En la causa de los animales late una potente redefinición de la masculinidad, una evolución fundamental que permitiría un salto cualitativo de la humanidad y que conecta con el ecofeminismo. La igualdad de género puede ser comprendida y concretada de dos maneras. La primera, androcéntrica, como inclusión de las mujeres en el modelo patriarcal, exige el abandono de la conexión emocional, la empatía y los valores del cuidado y la compasión por parte de las mujeres. La segunda, resultado de la conciencia crítica feminista y animalista, implica la adopción de esa conexión y esos valores por parte de todos los seres humanos independientemente de su sexo-género. Esta es una de las razones por las que veo con claridad un lazo profundo entre feminismo y animalismo, a pesar de todos los desencuentros, incomprensiones y errores de una y otra parte. Este lazo me parece uno de los temas fundamentales del ecofeminismo en tanto redefinición de nuestra especie.

La perspectiva ecofeminista implica la revisión de una serie de dualismos vertebradores de nuestro pensamiento: Naturaleza/Cultura, animal/humano, afectividad/intelecto, cuerpo/mente... A través de la Historia, estos dualismos jerarquizados han estado relacionados con la caracterización patriarcal de la diferencia de los sexos. Esta es una de las conexiones teóricas que hacen pertinente el enfoque feminista de la cuestión ontológica, ética y política de la relación del ser humano con los demás seres vivos.

El ecofeminismo demanda la reconciliación con los cuerpos y con su materialidad vulnerable. Recuerda que existe un amor sin odio, un deseo sin cosificación ni violencia. Al rechazar todo sistema de dominación, denunciando sus implicaciones patriarcales, el ecofeminismo llama a superar la violencia estructural contra la naturaleza humana y no humana, así como los prejuicios antropocéntricos que legitiman la violencia contra los animales. Lo que desde una perspectiva sexista y androcéntrica aparecía como sentimientos y actitudes femeninas o feminizadas, 
ridiculizadas, minusvaloradas, adquieren un nuevo status, ahora político, vinculado a una nueva comprensión del ser humano, de la diversidad y de esos otros seres a los que se suele incluir en los conceptos de "carne" y de "recursos naturales". El ecofeminismo nos orienta, así, hacia un mundo más justo en que la opresión no se legitime por prejuicios y jerarquías de sexo, raza, clase, opción sexual, edad o capacidades, en el que se respete a los animales no humanos como individuos capaces de sufrir física y emocionalmente y en el que se cuide de la Tierra que nos sustenta, pensando que no sólo es nuestra, sino de las generaciones futuras y del resto de los seres vivos. En Ecofeminismo para otro mundo posible hice una reinterpretación del mito griego del Minotauro con la que querría terminar estas líneas. La nueva Ariadna y el nuevo Teseo ya no odian la animalidad de sus cuerpos ni aceptan una cultura basada en la dominación y la violencia sobre el Otro reducido a mero cuerpo. Juntos entran en el laberinto del mundo y liberan al Minotauro porque saben que la humanidad plena no se alcanza por la negación y el odio al Otro vulnerable, sino por la luz de la empatía, la justicia y la compasión.

\section{REFERENCIAS BIBLIOGRÁFICAS}

ADAMS, Carol, DONOVAN (1995): Josephine (eds), Animals \& Women, Duke University Press, Durham and London.

AUSÍN, Txetxu, RODRÍGUEZ CARREÑO, Jimena (2012):“Introducción”, en RODRÍGUEZ CARREÑO, Jimena, Animales no humanos entre animales humanos, Colección Dilemata, Plaza y Valdés editores, pp.7-8.

AMORÓS, Cèlia (2005): La gran diferencia y sus pequeñas consecuencias para las luchas de las mujeres, Cátedra, Madrid.

AMORÓS, Cèlia (2008): Mujeres e imaginarios de la globalización, Rosario, Homo Sapiens Ediciones.

BATAILLE, Georges (1986) : La souveraineté, Euvres Complètes, Tome VIII, NTF, Paris, Gallimard.

BATAILlE, Georges (1976): L'Histoire de l'Erotisme, Euvres Complètes, Tome VIII, NTF, Paris, Gallimard.

BIANCHI, Bruna, en PULEO, Alicia, TAPIA GONZÁLEZ, Georgina Aimé,TORRES SAN MIGUEL, Laura, VELASCO SESMA, Angélica (coords.), Hacia una cultura de la sostenibilidad. Análisis y propuestas desde la perspectiva de género, Ed. Departamento de Filosofía de la Universidad de Valladolid con la colaboración de la Cátedra de Estudios de Género, pp.41-64. Puede consultarse en: http://www5.uva.es/depfilosofia/sites/default/files/documentos/Hacia\%20una\%20c ultura\%20de\%20la\%20sostenibilidad.pdf

DE MIGUEL, Ana (2008A): "Feminismo y juventud en las sociedades formalmente igualitarias”, Revista de Estudios de Juventud, n 83, pp. 29-45.

DE MIGUEL, Ana (2008B): La violencia contra las mujeres: tres momentos en la construcción del marco feminista de interpretación”, Isegoría: Revista de filosofía 


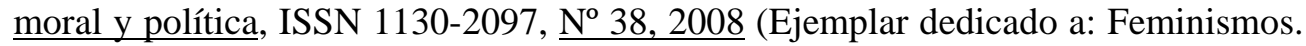
Nuevas tendencias), pp. 129-137

FEMENÍAS, María Luisa (2002): “Releyendo a Aristóteles desde la teoría de género”, Revista Laguna, 10; enero 2002, pp. 105-119.

FEMENÍAS, María Luisa (1996): Inferioridad y exclusión: Un modelo para desarmar, Buenos Aires, Grupo Editor Latinoamericano.

FEMENÍAS, María Luisa (2013), Multiculturalismo, identidad y violencia, Los ríos subterráneos, volumen II, Rosario, Prohistoria ediciones.

FRANCIONE, Gary (1998): "Personidad, propiedad y capacidad legal”, en CAVALIERI, Paola, SINGER, Peter, El Proyecto Gran Simio. La igualdad más allá de la humanidad, trad. C. Martín y C. González, Madrid, Trotta, pp.309-320.

HARAWAY, Donna (2004): Testigo_Modesto@SegundoMilenio. HombreHembra@_ Conoce_Oncoratón ${ }^{\circledR}$. Feminismo y tecnociencia, trad. Elena Torres, Editorial UOC, Barcelona.

HERRERA GUEVARA, Asunción (2014): Ilustrados o bárbaros. Una explicación del déficit democrático y eticomoral, Madrid-México, Plaza y Valdés editores.

LAGARDE, Marcela (2008): “Antropología, feminismo y política: violencia feminicida y derechos humanos de las mujeres", en BULLEN, Margaret, DIEZ MINTEGUI, Carmen (coord.), Retos teóricos y nuevas prácticas, San Sebastián, Ankulegi Antropologia Elkartea, pp.209-239.

LOPEZ PARDINA, Teresa (1998): Simone de Beauvoir. Una filósofa del siglo XX, Publicaciones de la Universidad de Cádiz.

MIEDZIAN, Myriam (1995): Chicos son, hombres serán. Horas y Horas, Madrid.

POSADA KUBISSA, Luisa (1994): “Un Gran Reserva francés frente al vino de mesa rousseauniano. Re-lectura feminista de la aristocrática revuelta libertina del siglo XVIII”, en ER. Revista de Filosofía. Año IX pp. 9-39.

POSADA KUBISSA, Luisa (2012): Sexo, vindicación y pensamiento, Madrid: Huerga \& Fierro editores.

PULEO, Alicia (2011): Ecofeminismo para otro mundo posible, Colección Feminismos, Madrid, Ed. Cátedra.

ROLDÁN, Concha (2013): "Ni virtuosas ni ciudadanas: inconsistencias prácticas en la teoría de Kant”, Ideas y valores, vol. LXII, suplemento nº 1, Bogotá, pp. 185 -203.

ROMERO, Rosalía (2015): "Inteligencia y sentimientos en la Filosofía de la Naturaleza del siglo XVI español”, en PULEO, Alicia, TAPIA GONZÁLEZ, Georgina Aimé,TORRES SAN MIGUEL, Laura, VELASCO SESMA, Angélica (coords.), Hacia una cultura de la sostenibilidad. Análisis y propuestas desde la perspectiva de género, Ed. Departamento de Filosofía de la Universidad de Valladolid con la colaboración de la Cátedra de Estudios de Género, pp.75-84.

Puede consultarse en: 
http://www5.uva.es/depfilosofia/sites/default/files/documentos/Hacia\%20una\%20c ultura\%20de\%20la\%20sostenibilidad.pdf

SEGATO, Rita (2006): "Qué es un feminicidio. Notas para un debate emergente”, en Revista Mora, Buenos Aires: Instituto Interdisciplinario de Estudios de Género/ Universidad de Buenos Aires, núm. 12, pp. 2-11.

SADE, Marqués de (1999): La filosofía en el tocador, trad. Ricardo Pochtar, Barcelona: Tusquets.

SEGATO, Rita (2013): Las nuevas formas de la guerra y el cuerpo de las mujeres, Tinta Limón Ediciones.

SHIVA, Vandana (1995): Abrazar la vida. Mujer, ecología y desarrollo, trad. Instituto del Tercer Mundo de Montevideo (Uruguay), Madrid, Cuadernos inacabados 18, ed. horas y HORAS.

VALCÁRCEL, Amelia (1997), La politica de las mujeres, Colección Feminismos, Madrid, Ed. Cátedra.

VALCÁRCEL, Amelia (2008): Feminismo en el mundo global, Colección Feminismos, Madrid, Ed. Cátedra.

WOLLSTONECRAFT, Mary (1994): Vindicación de los Derechos de la Mujer. Trad. Carmen Rodríguez Jimeno. Colección Feminismos Clásicos, Madrid: Cátedra. 